\title{
Operation and testing for product innovation
}

\author{
P. Gallo \\ Department of Architecture, Florence University, Italy
}

\begin{abstract}
What is the role of the innovation for systems and components in the future? Will we be able to change the existent technological systems and to develop innovative products in order to influence the building market or create really new ideas capable of change to the life style of the people? The objective is to achieve a sustainable good quality construction as a continuous process starting from the new characteristics and new opportunities for the enterprises and develop new components with high efficiency in order to satisfy the construction market and to meet the demand for high-performance by the users. To achieve this, a close relationship between the research world and manufacturing companies play a key role, especially in the development phase of new performing products and for the improvement of new architectural solutions studied for their integrability in the buildings.
\end{abstract}

Keywords: products innovation, construction market, research and innovation, energy saving, sustainable construction.

\section{Introduction}

Building sector energy consumption grew $18 \%$ between 2000 and 2010, to reach $117 \mathrm{EJ}$ - around one-third of global final energy use, producing about one-sixth of end-use direct $\mathrm{CO}_{2}$ emissions. Several key factors influence the evolution of building energy consumption and emissions, including population growth, which increases demand for residential buildings and services. In fact the global population increased by $14 \%$ from 2000 to 2011 , to almost 7 billion, and is expected to rise by $10 \%$ from 2011 to 2020 , to reach 7.6 billion. The proportion of the world's population living in urban areas has risen from $47 \%$ in 2000 to slightly more than half today. By 2020 , that share is expected to be $56 \%$. So the buildings are responsible for the largest share of energy consumption and associated greenhouse gas $\left(\mathrm{CO}_{2}\right)$ emissions and therefore building construction I 
a key sector to reach the long term climate and energy targets. The challenge of the future efforts of the construction sector should be properly addressed by policies in order to mobilize the market towards a low carbon society and trigger multiple benefits (such as the independence from energy imports from politically unstable areas, job creation, improved air quality and indoor comfort, reduced fuel poverty etc.).

Unfortunately, energy demand in the buildings sector is expected to increase by $6.6 \%$ to around $124 \mathrm{EJ}$ in 2020 , but deep emissions reductions can be achieved, at low cost based on existing technologies and by a construction market innovation with more problem regarding the investments; the challenge is to ensure that appropriate policies are in place to realise this potential through energy savings in new and existing buildings. In summary, the building sector is key to achieving the EU's energy, climate and resource efficiency long-term strategies: to reach the long-term decarbonisation goals, the $\mathrm{EU}$ [1] identified potential $\mathrm{CO}_{2}$ emissions reduction of $88 \%$ to $91 \%$ by 2050 compared to 1990 levels, related to the residential and services sectors. in addition, the Energy Roadmap 2050 [2] considers that the high "energy efficiency potential in new and existing buildings is key" to reach a sustainable energy future in the EU, contributing significantly to the reduction of energy demand, the security of energy supply and the increase of competitiveness. Furthermore, the Roadmap to a Resource Efficient Europe [3] identifies buildings among the three key sectors responsible for $70 \%$ to $80 \%$ of all environmental impacts. Therefore, better construction and use of buildings in the EU would influence $42 \%$ of the final energy consumption, about $35 \%$ of the $\mathrm{CO}_{2}$ emissions, more than $50 \%$ of all extracted materials and could save up to $30 \%$ of water consumption. However, to unleash the full potential of energy savings related to buildings, the additional value of improved energy efficiency (e.g. improved indoor climate, reduced energy cost, improved property value, etc.) must be recognised, and the lifetime costs of buildings have to be considered rather than just focusing on investment costs. Over the last decade, building policies in the European Union increased in their scope and coverage and are moving towards an integrated approach taking into account the energy, environmental, financial and comfort related aspects [4].

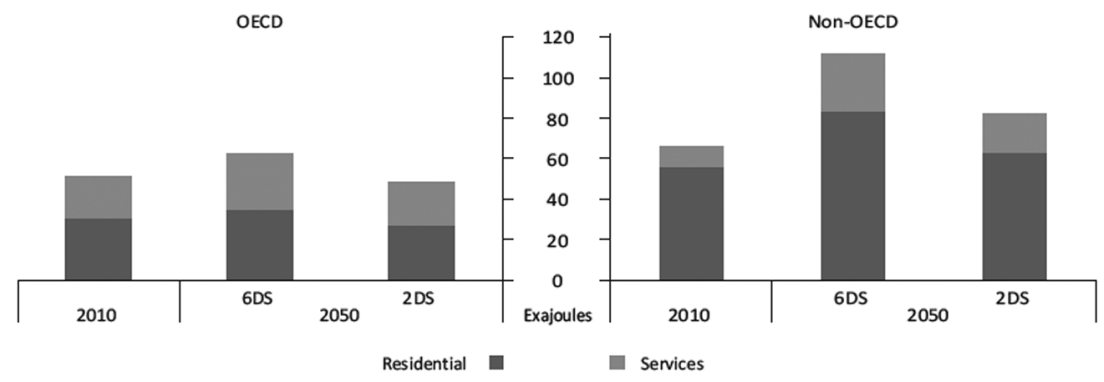

Figure 1: Buildings end-use energy by sector and the forecast by $2 \mathrm{D}$ and $6 \mathrm{D}$ scenario. (Source: EU Technology Roadmap - Energy Efficient Building Envelope.) 


\section{The innovation technology and research contribution}

The process of technological innovation is often described, for analytical and prescriptive purposes, as a linear process composed of several stages or steps that include research, development, demonstration, deployment and diffusion. Mapping innovation in the real world is clearly more complex, as the process of innovation is not a linear progression. Feedback occurs between the different stages of the process. For example, demonstration projects can result in significant changes to the product; feedback from the market and from technology users during the commercialisation and diffusion phases can lead to additional RD\&D (research development and demonstration), driving continuous innovation; as well as free-market competition at the later stages of the RD\&D chain, when technologies are closer to commercialisation, also plays an important role for continuous innovation.

\subsection{Accelerate innovation in energy and public activities of research, development and demonstration programs, investing in transition}

Governments should develop and implement strategic programs of energy research, relying on increased and sustained financial support. They should also consider the creation of joint efforts of RD\&D in order to take coordinated action, to avoid duplication, improve performance and reduce costs of the technologies in the first phase of innovation, including through the sharing of lessons learned from innovative models of RD\&D. Resource efficiency and technology innovation, in fact, can reduce costs, but often requires initial investments. UNEP (United Nations Environment Programme) estimate that the annual financing needs for making the world economy more resource efficient are very high (between US\$ 1.05-2.59 trillion), mainly from private sources. This will require not only spending for green solutions, but greening of all public and private investments. For this reason the European Council adopted the regulation laying down the EU's multiannual financial framework for 2014-20; a proposal for a Multiannual Financial Framework 2014-2020 that marks the end of two and a half years of negotiations and allows the new generation of EU spending programmes to be implemented as from 1 January 2014 that have already made major steps towards integrating resource efficiency in the EU budget. So, the rapid growth of global financing for clean energy shows how this shift in mindset is possible. However, unfamiliarity of financiers with risks and returns on investments in resource efficiency presents an obstacle to investment, uncertainty on policy direction and credibility adds financial risk, and the longer-term investments are often not favoured by the financial markets geared to short-term performance. The transition to a green and low-carbon economy will require significant innovation, from small incremental changes to major technological breakthroughs. At the same time we need a more comprehensive and credible knowledge base about how the natural systems react to the different pressures we exert on them. Basic and applied research should identify challenges and guide actions, including social sciences research to develop our understanding of behaviour. To trigger this push in 
research and innovation, the right set of incentives needs to be in place so that the private sector invests more in resource efficient research and innovation. Demand side measures will help create incentives for green innovation by building markets. Clear framework conditions are needed to increase investor certainty and better access to finance for companies making green investments that are seen as riskier or that have longer payback times.

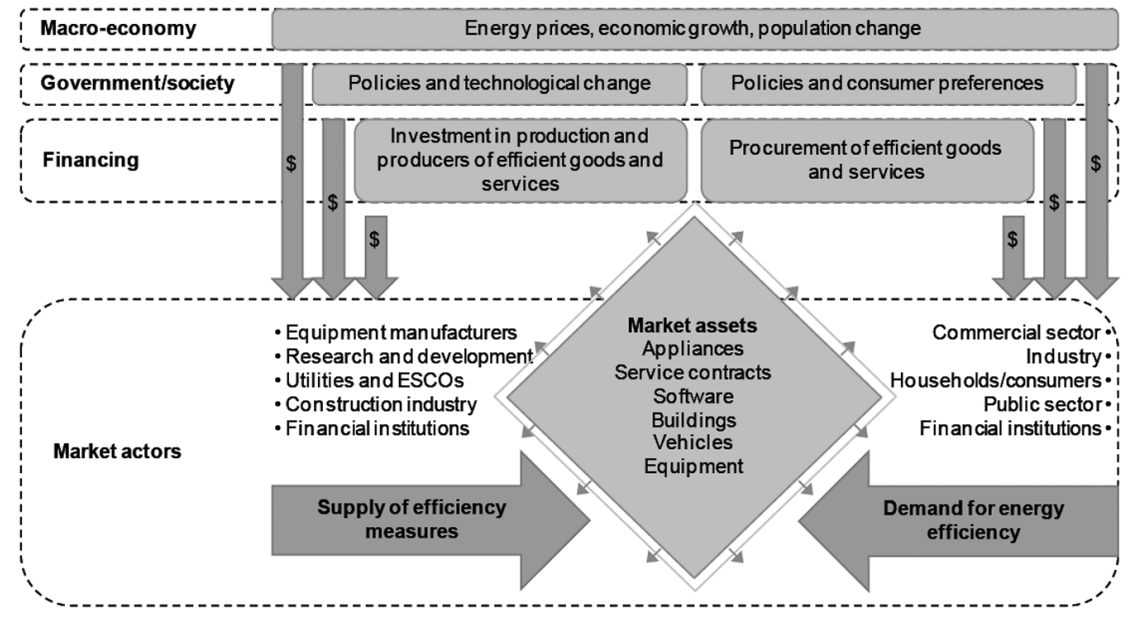

Figure 2: The market for energy efficiency.

\subsection{Research and innovation in the building sector: the role of the building envelope}

Near-zero energy consumption in new - and existing - buildings and communities is possible. Designing a carefully chosen research and development strategy will enable the building industries to move from incremental - to substantial - energy savings and reductions in greenhouse gas emissions. The aim of the implementing agreement for a programme of research and development on energy in buildings is to take advantage of energy-saving opportunities to remove technical obstacles to market penetration of new energy conservation technologies for community systems and residential, commercial, and office buildings. To implement this strategy, research activities have to focus on dissemination, decision-making and building systems. When buildings are constructed or renovated, a whole-building perspective is preferred, which involves considering all parts of the building and the construction process to reveal opportunities to improve energy efficiency. Numerous whole-building perspectives and policy mechanisms exist, such as building performance certificates [5] and whole-building labelling programmes. In these perspectives, detail the building envelope's impact on energy consumption should not be underestimated [6]. While whole-building approaches are ideal, every day building envelope components are upgraded or replaced using technologies that are often less efficient than the best options that will be available 
if we invest in the innovation. These advanced options, which are the primary focus of the future in the construction, are needed not only to support wholebuilding approaches but also to improve the energy efficiency of individual components:

- high levels of insulation in walls, roofs and floors, to reduce heat losses in cold climates, optimised through life-cycle cost (LCC) assessment;

- high-performance windows, with low thermal transmittance for the entire assembly (including frames and edge seals) and climate-appropriate solar heat gain coefficients;

- highly reflective surfaces in hot climates, including both white and "coolcoloured" roofs and walls, with glare minimized;

- properly sealed structures to ensure low air infiltration rates, with controlled ventilation for fresh air;

- minimisation of thermal bridges (components that easily conduct heat), such as high thermal conductive fasteners and structural members, while managing moisture concerns within integrated building components and materials.

Analysis of building envelopes is complicated by the extreme global diversity of building materials, climates, and standards and practices of building design and construction, but it is vital to ensure for new and retrofit buildings the use the most efficient technologies. So, the suitability of energy-efficient technologies depends on the type of economy, climate and whether the materials are being used for new buildings or retrofits. To achieve the large energy savings that efficient building envelopes can offer, full market saturation of high-priority, energy-efficient building materials is essential. Not only but is more important to invest in RD\&D on the following technologies that will lead to greater returns on investment:

- highly insulated windows;

- advanced, high-performance, "thin" insulation;

- less labour-intensive air sealing, and lower-cost validation testing;

- lower-cost automated dynamic shading and glazings;

- more durable and lower-cost reflective roof materials and reflective coatings.

Cost is a primary barrier to greater application and in some cases there are also concerns about long-term performance. There also is a lack of knowledge about innovative applications, and detailed design guidelines are limited. Greater effort is needed to highlight applications that are viable in market terms, such as locations in buildings with space limitations that will usually require a combination of high thermal performance insulation with lower material cost. Also, a systems perspective can allow for high-performance insulations to reduce labour costs, especially for building renovations (e.g. interior wall insulation in historic buildings), so cost-effectiveness does not have to be limited just to the material cost of a system. 


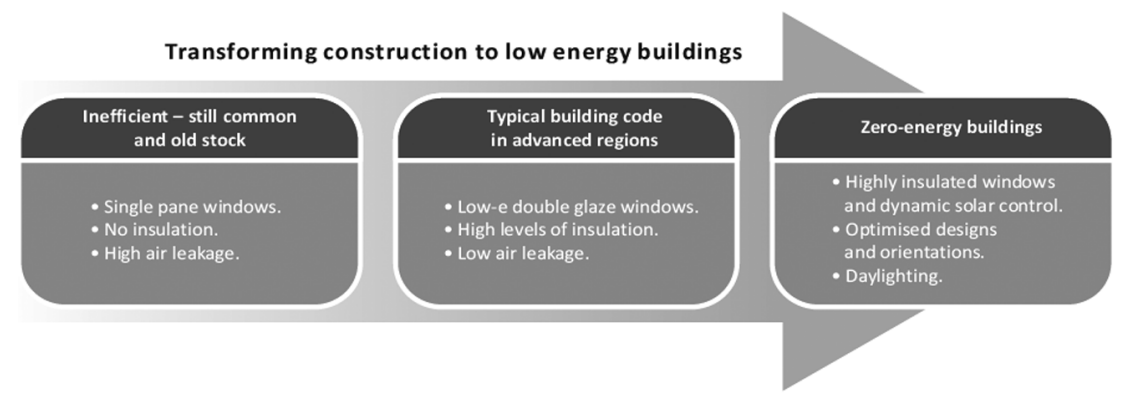

KEY POINT: the world needs to shift from very old buildings to modern buildings, and then to low-energy or zero-energy buildings.

Figure 3: Progression construction of building envelopes from old stock to future technology. (Source: IEA Report Technology Roadmap Energy efficient building envelopes.)

\section{New opportunities to satisfy the construction market for high-performance buildings}

What is the role of the innovation for systems and components in the future? Will we be able to change the existent technological systems and to develop innovative products in order to influence the building market or create really new ideas capable of change to the life style of the people? The answer to this questions is achieve a sustainable good quality construction as a continue process starting from the new characteristics and new opportunities for the enterprises and develop new components with high efficiency in order to satisfy the construction market and to

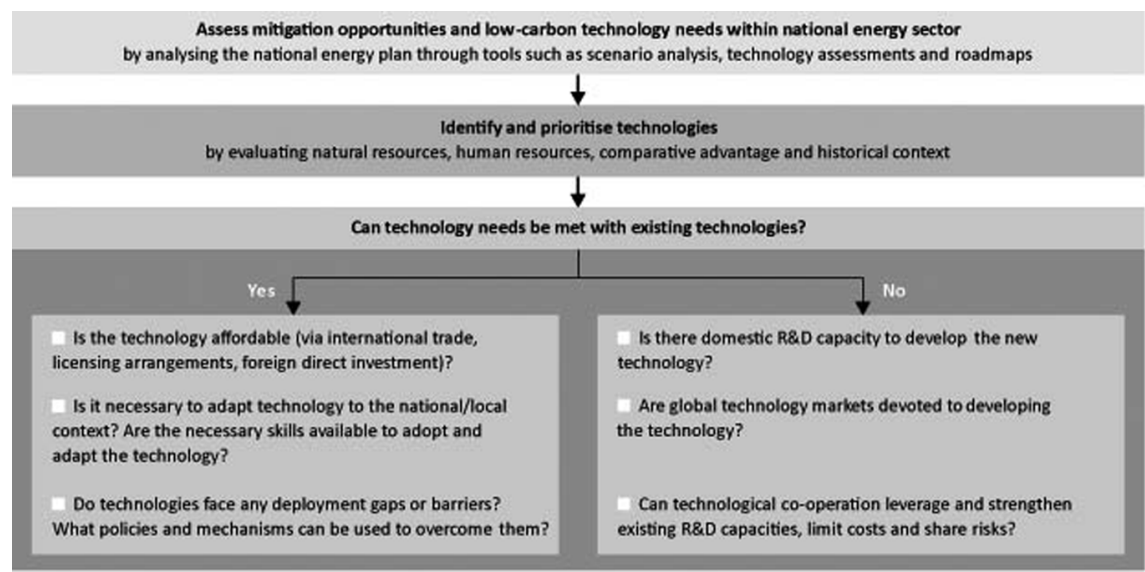

Figure 4: The suitability of energy-efficient technologies. (Source: Tracking Clean Energy Progress 2013 - IEA Report.) 
meet the demand for high-performance by the users. Market barriers preventing the adoption of energy-efficient buildings or building materials can be real or perceived. As well as simple failures such as a lack of knowledge about alternative options, they can include concerns about the performance, expected energy savings, reliability and service life of a new product. Some new construction materials and approaches oblige builders to completely change the way a building is erected.

Barriers in emerging markets can include import tariffs, a lack of product performance metrics and a lack of installation procedures. In many countries there are also institutional barriers such as lack of government oversight or interest, lack of appropriate market signals to promote efficiency, and lack of basic infrastructure. To deploy energy-efficient buildings, several institutional and market barriers need to be overcome. The following core elements should serve as good starting points for policy makers in regions where construction practices do not typically include energy-efficiency strategies:

- there is a large array of technical requirements to enable the installation of more efficient building envelopes. These include proper test performance metrics and associated testing equipment so that third-party test ratings, certificates and labels can be established. Skilled labour is essential to conduct tests, assess alternative building solutions, promote efficient building policy, install new materials, conduct inspections and ensure compliance. It is also vital to make available general education materials such as guidelines adapted for the specific markets; energy calculators based on local climate, energy prices and occupant behavior; and an overall improved knowledge base of more efficient options;

- while demonstration buildings can be built with materials imported from distant places, for energy-efficient buildings to become viable the materials need to be manufactured much closer to the construction region, since shipping costs for large, heavy materials can be prohibitively high;

- to ensure that factories are built that can produce commodity materials on a large scale, governments need to give clear signals about their interest in promoting efficient building envelopes, and often other support such as market-based or higher energy prices (higher tariffs). Policy makers need to have an open dialogue with the building material industry about key elements that will help drive investment. Manufacturing building materials domestically, or at least regionally, creates jobs not only in local manufacturing but also for global investors involved in specialised tooling and unique raw materials.

In this contest, in Italy, to overcome these barriers and stimulated by the scenarios provided by the European Community, the regional administration of Tuscany, has funded a research project "Abitare Mediterraneo" (www.abitaremediterraneo.eu) aimed to develop synergy between industrial companies, builders and research centres, to increase competitiveness in building sector and meet European and National standard requirements. The project aimed to increase the energy saving in Mediterranean climate, focusing on summer 
comfort, developing and testing innovative solutions with national and EU companies. The research has developed advanced tools, as a Database, a Test Cell, and a new Spin-off on sustainable architecture and innovative products. In detail, the multimedia library create a complete tool to help designers, companies and public administrations to design building in Mediterranean climate.

The database structure have developed a system to surfing inside a specific meta-design, technical and performance solutions of building and envelop in relationship with the energy legislation.

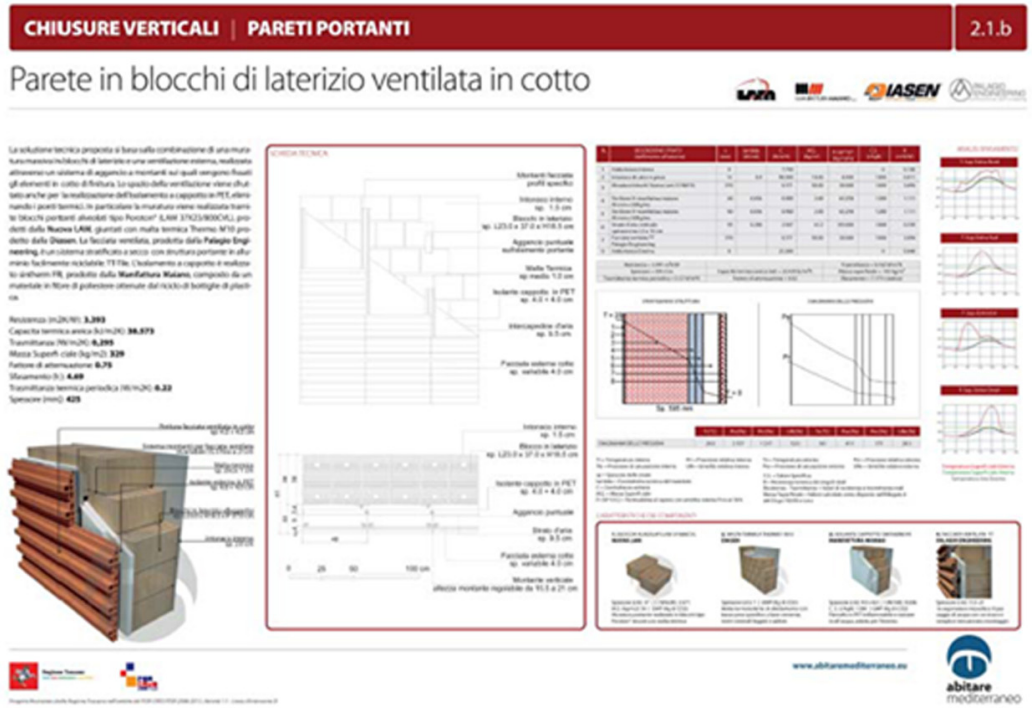

Figure 5: The database web screen with the products and the specific performance that characterize them. (Source: www.abitaremediterraneo.eu)

The catalog of meta-design solutions "Abitare Mediterraneo" analyzes performance requirements of specifics of building innovative components for Mediterranean climate. This library is a reference point for designers that approaching not only at energetic projects but also at projects were, new pattern of space, contribute at indoor comfort. The database want create a map of the building system were technical and innovative typological solution are connoted by the requirements of space and performance of solution. Inside the database it's possible choose, within a large group of products for building, components and technological systems (new and existent) more efficient to energy saving: the user can develop meta-design solutions in terms of performance and in relation to environmental characteristics of Mediterranean areas. For every solution is possible identify the most important requirements and some meta-design indications, connected with the technical solution database where it is possible to found different solution for answer at requirements indicated. 
Another important result of Abitare Mediterraneo research, was been the construction of an outdoor Test Cell to assess the dynamic thermal behavior of building surfaces; an instrument for giving the opportunity principally to local building market to test new products that needs to be used in Mediterranean Climate, products that are able to reduce annual energy consumption in buildings working with a sufficient insulation level and appropriate thermal inertia if necessary. In fact, with this tool, can be run tests on innovative exterior wall elements, in exterior ambient conditions and the data that can be obtained, include thermal damping factor, delays, solar aperture factor and $U$ value. The test cell features instruments for multi-channel monitoring a weather station and their own analysis software. Outdoor test cells, where there is a high degree of control of the indoor environment, well-specified constructions and high levels of instrumentation, can certainly fill the gap between laboratory testing and full-scale building testing. In fact the main use of testing in outdoor test cells is the link with simulation modelling.

The innovative perspective is that dynamic simulation programs have improved in capability and validity and can therefore be used with some confidence in predicting energy and environmental performance of buildings. However, where a new component is under development, for example an advanced glazing, a hybrid photovoltaic module or shading component, then high quality datasets from outdoor experiments can be used to ensure that the simulation program is capable

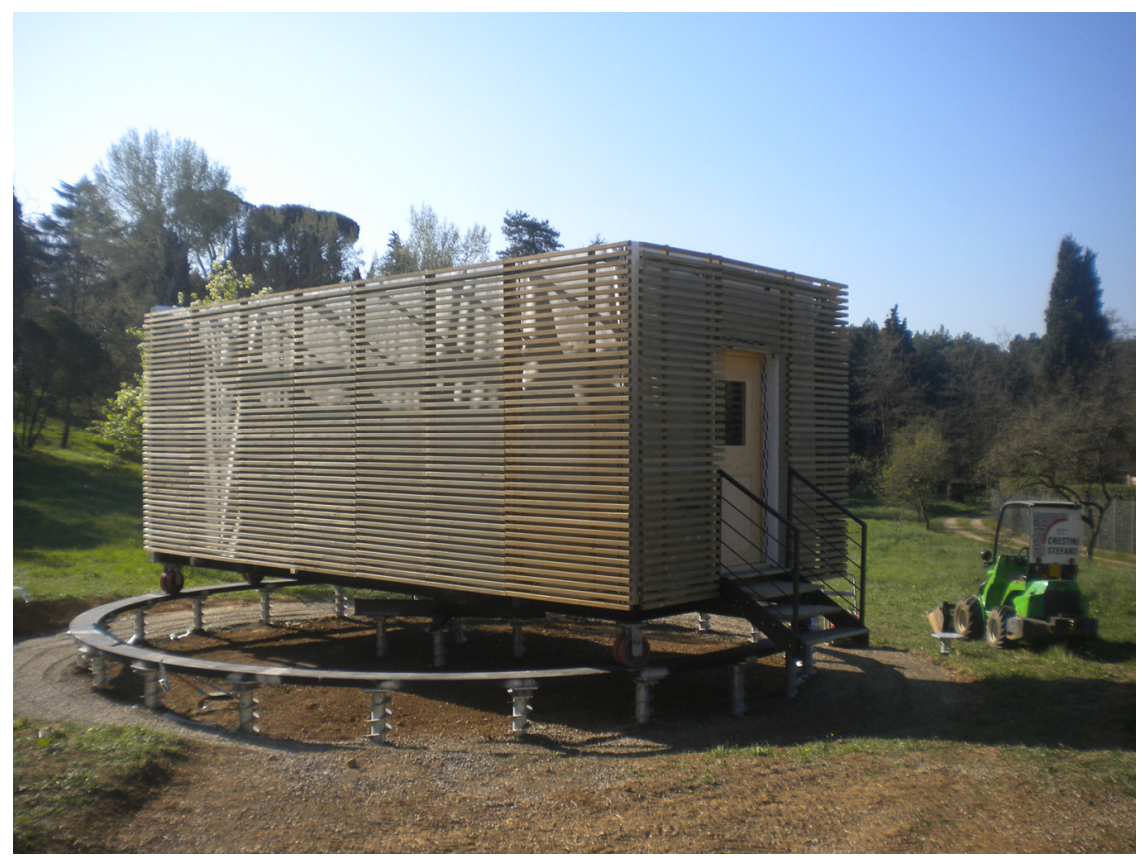

Figure 6: The outdoor Test Cell realised in Italy (Florence) within the Abitare Mediterraneo project. (Source: www.abitaremediterraneo.eu) 
of modelling that component. If so, it is considered that the simulation program can then be used to model the component when integrated into a full-scale building.

Basically the principal mission of this research programme has been to develop and facilitate the integration of new technologies and processes for energy efficiency and conservation into healthy, low emission, and sustainable buildings and communities, through innovation and research. So the outdoor test cell realized in Italy within the Abitare Mediterraneo project, is a point of reference for companies and manufacturers of innovative components; a technology lab with an extensive program of service and open to all producers who wish to verify the performance of new products for the building to be placed on the market to promote energy conservation and sustainability in construction

\section{Results and discussion}

With the Test Cell lab, based on full scale dynamic measurements, is possible to develop the necessary knowledge, tools and networks to achieve reliable in-situ dynamic testing and data analysis methods that can be used to characterize the actual energy performance of building components and whole buildings. The main objectives in fact, are:

- work out common quality procedures for dynamic full scale testing to come to a better performance analysis;

- develop models to characterize and predict the effective thermal performances of innovative building components and whole buildings.

To reduce the energy use of the buildings and communities industrialized, many industrialized countries have imposed stringent requirements for new developments. In most cases, evaluation and labeling of energy performance of buildings are carried out at the design phase. Several studies have showed, however, that the actual performances after construction may deviate significantly from this theoretically designed performance. As a result, there is a growing interest in full scale testing of components and whole buildings characterize their actual thermal performance and energy efficiency. This full testing approach is not only of interest to study building components performance under actual conditions, but is also a valuable and necessary tool to deduce simplified models for advanced component and systems to integrate them into building simulation models. The same is true to identify suitable models to describe the thermal dynamics of whole buildings including their energy systems. It is clear that quantifying the actual performance of buildings, verifying calculation models and integrating new advanced energy solutions for nearly zero or positive energy buildings can only be affectively realized by in situ testing and dynamic data analysis. But, practice shows that the outcome of many on site activities can be questioned in terms of accurate and reliability. Full scale testing requires quality during all stage of approach, starting with the test environment, such as test cell or real buildings, accuracy of sensor and correct installation, data acquisition 
software, and so on. It is crucial that the experimental setup (for example test layout imposed boundary conditions for testing) is correctly designed, and produces reliable data. As soon as the required quality is not achieved at one of the stages, the results become inconclusive or useless. The outputs can then be used in dynamic data analysis based on advanced statistical methods to provide a characteristics with reliable accuracy intervals and finale use of results, to qualify the new products for the construction industry to launch an entirely competitive market, able to increase not only the industrial production, but above all, energy quality of buildings

\section{Conclusion}

Innovation within a project, company and occupational industry provides the opportunity to realize significant benefits and, in a competitive market, is a requirement for continued existence. All companies must innovate at some level in order to stay competitive. Innovation in the construction industry may take place at a lower rate compared to other industries due to the structure and characteristics of the industry and projects, but it does, and must, occur in a competitive market.

Product innovation is an important activity in corporate entrepreneurship and technology management. The successful introduction of new products into the market is a critical factor for the survival and growth of companies $[6,7]$. However, the increasingly dynamic and turbulent environment in which firms compete makes the commercialization of a new product not only a necessary, but also a risky venture.

Anyway, to unleash the full potential of energy savings related to buildings, the additional value of improved energy efficiency (e.g. improved indoor climate, reduced energy cost, improved property value, etc.) must be recognised, and the lifetime costs of buildings have to be considered rather than just focusing on investment costs. Over the last decade, building policies in the European Union increased in their scope and coverage and are moving towards an integrated approach taking into account the energy, environmental, financial and comfort related aspects

\section{References}

[1] EU Roadmap for moving to a competitive low carbon economy in 2050 (COM, 2011a), OECD/IEA, Paris.

[2] Employment Effects of selected scenarios from the Energy roadmap 2050. Final report for the European Commission (DG Energy), (COM, 2011b).

[3] EU Roadmap to a Resource Efficient Europe (COM, 2011c), European Commission, Brussels.

[4] Tracking Clean Energy Progress 2013 IEA Input to the Clean Energy Ministerial, IEA report 2013.

[5] IEA (2010a), Energy Technology Perspectives: Scenarios \& Strategies to 2050, OECD/IEA, Paris. 
[6] IEA Report Technology Roadmap Energy efficient building envelopes, OECD 2013, France.

[7] Crawford, M. and Di Benedetto, A. 2008. New Products Management. Ninth Edition. New York, NY: McGraw-Hill.

[8] Jerry (Yoram) Wind, Vijay Mahajan (1997), Issues and Opportunities in New Product Development: An Introduction to the Special Issue, Journal of Marketing Research, 1-12.

[9] Abitare Mediterraneo Project. www.abitaremediterraneo.eu 